\title{
Influences of Parental Snacking-Related Attitudes, Behaviours and Nutritional Knowledge on Young Children's Healthy and Unhealthy Snacking: The ToyBox Study
}

\author{
Edward Leigh Gibson 1,*D, Odysseas Androutsos ${ }^{2}$, Luis Moreno ${ }^{3,4,5}$, \\ Paloma Flores-Barrantes ${ }^{3,4,5}$ D , Piotr Socha ${ }^{6}$, Violeta Iotova ${ }^{7}$, Greet Cardon ${ }^{8}$ (D), \\ Ilse De Bourdeaudhuij ${ }^{8}$, Berthold Koletzko ${ }^{9}$, Simona Skripkauskaite ${ }^{1}$ (D, \\ Yannis Manios ${ }^{10}$ and on behalf of the Toybox-study Group ${ }^{\dagger}$ \\ 1 Department of Psychology, University of Roehampton, London SW15 4JD, UK; \\ s.skripkauskaite@bangor.ac.uk \\ 2 Department of Nutrition and Dietetics, School of Physical Education, Sport Science and Dietetics, University \\ of Thessaly, 42132 Trikala, Greece; oandroutsos@uth.gr \\ 3 GENUD (Growth, Exercise, NUtrition and Development) Research Group, Faculty of Health Sciences, \\ University of Zaragoza, Edificio del SAI, C/Pedro Cerbuna s/n, 50009 Saragossa, Spain; \\ lmoreno@unizar.es (L.M.); pfloresbarrantes@gmail.com (P.F.-B.) \\ 4 Instituto Agroalimentario de Aragón (IA2), 50013 Saragossa, Spain \\ 5 Fundación Instituto de Investigación Sanitaria Aragón (IIS Aragón), 50009 Saragossa, Spain \\ 6 The Children's Memorial Health Institute, 04-730 Warsaw, Poland; p.socha@ipczd.pl \\ 7 Department of Pediatrics, Medical University of Varna, 9002 Varna, Bulgaria; violeta.iotova@mu-varna.bg \\ 8 Department of Movement and Sports Sciences, Ghent University, 9000 Ghent, Belgium; \\ greet.cardon@ugent.be (G.C.); Ilse.Debourdeaudhuij@UGent.be (I.D.B.) \\ 9 Dr von Hauner Children's Hospital, LMU-Ludwig-Maximilians-University at Munich, D-80337 Munich, \\ Germany; Berthold.Koletzko@med.uni-muenchen.de \\ 10 Department of Nutrition and Dietetics, School of Health Science and Education, Harokopio University, \\ 17671 Athens, Greece; manios.toybox@hua.gr \\ * Correspondence: 1.gibson@roehampton.ac.uk \\ + Membership of ToyBox-study group is provided in the Acknowledgments.
}

Received: 29 December 2019; Accepted: 4 February 2020; Published: 7 February 2020

Abstract: This study investigated parental influences on preschool children's healthy and unhealthy snacking in relation to child obesity in a large cross-sectional multinational sample. Parents and 3-5 year-old child dyads $(n=5185)$ in a kindergarten-based study provided extensive sociodemographic, dietary practice and food intake data. Parental feeding practices that were derived from questionnaires were examined for associations with child healthy and unhealthy snacking in adjusted multilevel models, including child estimated energy expenditure, parental education, and nutritional knowledge. Parental healthy and unhealthy snacking was respectively associated with their children's snacking (both $p<0.0001$ ). Making healthy snacks available to their children was specifically associated with greater child healthy snack intake $(p<0.0001)$. Conversely, practices that were related to unhealthy snacking, i.e., being permissive about unhealthy snacking and acceding to child demands for unhealthy snacks, were associated with greater consumption of unhealthy snacks by children, but also less intake of healthy snacks (all $p<0.0001$ ). Parents having more education and greater nutritional knowledge of snack food recommendations had children who ate more healthy snacks (all $p<0.0001)$ and fewer unhealthy snacks $(p=0.002, p<0.0001$, respectively). In the adjusted models, child obesity was not related to healthy or unhealthy snack intake in these young children. The findings support interventions that address parental practices and distinguish between healthy and unhealthy snacking to influence young children's dietary patterns. 
Keywords: child obesity; snacking; preschool children; nutrition; parents; feeding practices; Europe

\section{Introduction}

Trends in childhood obesity are a concern in many countries, with evidence for increasing prevalence of obesity, even in preschool children [1]. Numerous interventions have been attempted, addressing eating, drinking, and activity energy-balance related behaviours, primarily in school-aged children, but with mixed success [2-4]. In younger children, family environment, and particularly parental feeding practices, are strong predictors of both children's diet [5] and adiposity [6], and so successful interventions should include these aspects.

Snacking is an important energy-balance related dietary behaviour in children: young children have proportionately the highest nutritional and energetic requirements of any stage of the lifespan [7]; thus, frequent eating, including snacking between meals, is typical, easily reinforced, and avoids acute nutritional deficits that might otherwise limit physical and psychological development [8,9]. Therefore, snacking can substantially contribute to daily energy intake; for example, one recent comparison of four national nutritional surveys of 4-13-year-old children found that snacking provided up to one-third of energy intake [10]. Furthermore, there is concern that children's choice of snacks are often particularly high in sugar and fat $[11,12]$. Therefore, it is important to distinguish between snacking on foods with a healthy nutrient profile (e.g., fruit and vegetables, unsweetened dairy) from those with unhealthy profiles (e.g., those high in fat, sugar, and/or salt, but low in essential nutrients), and to understand their determinants [8].

The strong influence of parental eating behaviour and feeding practices on children's diet is well established [6,13]. However, there is less understanding of parental influences, specifically on children's snacking behaviours [14,15], i.e., energy consumption between meals, particularly in relation to how different healthy or unhealthy snacking habits, might contribute to children's risk of obesity [16]. A recent systematic review of 47 studies on parenting practices that included information on children's snacking found that 39 of these studies concerned parenting practices not specifically related to snacking [17]. Furthermore, the most consistent significant associations were that parental restriction of food was related to higher levels of child snacking, which suggests reactive rather than proactive parenting [17]. This reactive parenting appears to be a common response [18], with such parental food restriction also being positively associated with child obesity [19]. By contrast, there is a paucity of evidence for beneficial effects of proactive parenting, such as modelling, on children's snacking per se, although the shared family environment is known to explain most of the variance in snack preferences in preschool children $[17,20]$.

Baseline data from the ToyBox-study (www.toybox-study.eu), a six-country kindergarten-based, family-involved intervention to improve energy-balance related behaviours in preschool children [21], provided the opportunity to examine cross-sectional relationships between parental feeding practices and their children's snacking, in a large and diverse international, yet thoroughly observed, sample. ToyBox-study surveyed parents from six European countries in detail about their attitudes to snacking, their practices in feeding their children, and their own and their children's frequencies of healthy and unhealthy snacking. At the time, these data were collected, there had been little research into relations between parental practices and young children's snacking behaviours, with the exception of the development of the Toddler Snack Food Feeding Questionnaire [22]. Moreover, that study only examined associations between parental practices and unhealthy snacking, and found little association with child obesity. More recently, Davison et al. [15] conducted a qualitative study while using semi-structured interviews of caregivers' snack feeding practices for preschool children. They proposed four dimensions: autonomy support (praise/ support/modelling of healthy snacking/child-centered provision); structure (planning/ routine/availability/monitoring); coercive control (snacks to manage behaviour/unilateral decisions/restriction/pressure); and, permissiveness 
(no rules/disinterest/emotion-based feeding). By comparison, a quantitative cluster analysis of a 21-item 'Comprehensive Snack Parenting Questionnaire' [23] reported four-dimensional clusters of parental practices: "high covert control and rewarding", "low covert control and non-rewarding", "high involvement and supportive", and "low involvement and indulgent". Parents practising "high involvement and supportive" feeding had children who tended to eat energy-dense snacks least often.

The ToyBox-study questionnaires completed by parents included various items that were related to snacking practices, and in relation to parental nutritional knowledge. Our interest was primarily in examining supra-country patterns for both healthy and unhealthy snacking using hierarchical modelling to control for country differences, although some differences in unhealthy snacking between countries have been reported for the ToyBox-study [24]. Thus, as in the above studies, the present study focused on examining the dimensional structure of responses (grouping of item response variation) on items that were related to parental feeding practices, as being behaviourally and psychometrically more meaningful than examining associations with individual questionnaire items. Therefore, we applied multilevel modelling to determine the independent influences of these parents' feeding practices, their own snacking, and the parents' nutritional knowledge in relation to snacks, on both healthy and unhealthy snacking by their children.

\section{Materials and Methods}

\subsection{Study Design}

The Toybox-study was an intervention with a cluster randomized design, having two phases of data collection, at the baseline and at post-intervention (2012-2013). A detailed description of the ToyBox-study design is provided elsewhere [25]. The present study considers the baseline data only. The missing data were not replaced. The ToyBox-study adhered to the Declaration of Helsinki and the conventions of the Council of Europe on human rights and biomedicine. All the countries (Belgium, Bulgaria, Germany, Greece, Poland, and Spain) obtained ethical clearance from the relevant ethical committees and local authorities; all the parents/caregivers provided a signed consent form before being enrolled in the study.

\subsection{Participants}

Parents or primary caregivers (97\% mothers) and their children attending kindergarten while aged 3.5-5.5 years old were recruited to the ToyBox-study, a European Commission-funded large-scale kindergarten-based, family-involved intervention in preschool children, and their families from six European countries: Belgium, Bulgaria, Germany, Greece, Poland, and Spain.

The study sample was composed of preschool children and their families, who were approached via kindergartens that were recruited from three socioeconomic levels of municipalities within each country. All the data presented in the present study were obtained between May and June 2012, while using standard methods and equipment that were applied by trained researchers. Initially, 10,632 parents/caregivers of preschoolers from six European countries provided written informed consent to participate in the ToyBox cross-sectional study. Of these, 8117 parents/caregivers (76.3\%) filled in the CORE Questionnaire, and 7244 parents/caregivers (68.1\%) filled in the Food Frequency Questionnaire [24]. Demographic information is not available on those parents who failed to participate in questionnaire completion.

Family, sociodemographic, and behavioural data were self-reported by parents and caregivers via the CORE-questionnaire (CORE-Q), including their years of education, weight and height, and their child's sex, and details regarding parental feeding practices and attitudes, which were derived from extensive focus group research and shown to be reliable [26]. Parents also completed a highly structured food frequency questionnaire concerning their child's diet (Child FFQ); this has been validated in a subsample from the ToyBox-study, with moderate to good validity, including for snack foods, such as biscuits [27]. As this study specifically concerns the influence of parental feeding practices, to improve 
the validity of any associations between the feeding practices and/or obesity of the primary carer and that of the child, we only analysed parent/guardian-child dyads, where the primary carer who completed the questionnaires was also the person who usually cooked for the child and fed the child, as determined by the responses to relevant questions on the CORE-Q. The questionnaires can be found online (www.toybox-study.eu) and detailed information on the development, test-retest reliability, and validity has been described elsewhere $[26,28,29]$.

\subsection{Predictor Variables}

\subsubsection{Derivation of Scales for Parental Attitudes and Practices Regarding Snacking}

At the time this study was designed, behavioural models specifically characterising parental feeding practices in relation to child snacking were not available, although three questionnaires have been recently developed in this area $[22,23,30]$. Nevertheless, as parental practices were of interest in the ToyBox-Study, the CORE-Q contained relevant questions. Although the large multinational sample and intervention design did not allow for a standard psychometric validation, we were interested in examining the possible dimensional structure of the set of questions on this topic, and so applied psychometric analyses to determine this. Thus, suitable items were selected from the CORE-Q based on representing specific beliefs, attitudes, and practices of the parents in regard to their child's snacking behaviour. This section of the questionnaire was headed "Please read the following statements and tick the boxes most appropriate to your situation for morning, afternoon and evening snacks (responses on a five-point Likert scale, from $1=$ "strongly disagree" to $5=$ "strongly agree"). An initial item analysis was carried out, and after examination of the correlation matrix, some items were excluded as being too similar to others: the remaining 12 items had acceptable distributions, with skewness ranging from 0.05 to -1.06 , means ranging from 2.12 to 4.18 (on a 1-5 scale), and the smallest $\mathrm{SD}=$ 0.78. Therefore, Principal Components Analysis (PCA) was used to assess these items for potential contribution to unique scales with Promax non-orthogonal rotation. The pattern matrix (Table 1) suggested four factor components (2-4 items per factor with loadings above 0.40). These are labelled as follows: component 1 (3 items) = 'Healthy snack provision'; component 2 ( 2 items) = 'Permissive healthy snacking'; component 3 (3 items) = 'Unhealthy snacks child responsive'; and, component 4 (4 items) $=$ 'Permissive unhealthy snacking'. Thus, the scale scores were generated from the means of the respective items, having reverse-scored items 9 and 12 (Table 1) for the component 4 scale. These four derived variables were normally distributed. For scales consisting of 2-4 items only, within-scale reliability is likely to be limited [31], but the interest here is in dimensionality derived from the PCA [32]; nevertheless, Guttman's $\lambda_{2}$ values [33] were computed, as follows: healthy snack provision $\lambda_{2}=0.60$; permissive healthy snacking $\lambda_{2}=0.73$; unhealthy snacks child responsive $\lambda_{2}=0.51$; and, permissive unhealthy snacking $\lambda_{2}=0.49$.

Table 1. Pattern matrix from PCA with Promax rotation ${ }^{\mathrm{a}}$ of parent/carer attitudes and practices from CORE-questionnaire (CORE-Q) item responses related to child snacking.

\begin{tabular}{|c|c|c|c|c|}
\hline \multirow{2}{*}{ CORE-Q Items } & \multicolumn{4}{|c|}{ Component } \\
\hline & 1 & 2 & 3 & 4 \\
\hline 1. I make dairy snacks regularly available for my child & 0.812 & & & \\
\hline 2. I make cereals/bread snacks regularly available for my child & 0.727 & 0.136 & 0.141 & \\
\hline 3. I make fruit or vegetables snacks regularly available for my child & 0.625 & & -0.276 & \\
\hline 4. My child is allowed to eat dairy or cereals/bread as snacks without asking & 0.141 & 0.849 & & \\
\hline 5. My child is allowed to eat fruits or vegetables as snacks without asking & & 0.838 & & \\
\hline 6. If I prohibit my child to eat a sweet or salty snack, I find it difficult to stick to my rules if he/she starts nagging & -0.119 & 0.106 & 0.733 & \\
\hline 7. I find it difficult to restrain myself from eating sweet or salty snacks because of the presence of my child & 0.168 & -0.169 & 0.686 & \\
\hline 8. I give sweet or salty snacks to my child as a reward or to comfort him/her & -0.126 & & 0.663 & \\
\hline 9. My child is allowed to eat sweet or salty snacks only at certain occasions i.e., birthdays & 0.228 & & 0.177 & -0.726 \\
\hline 10. I make sweet or salty snacks regularly available for my child & 0.145 & & 0.153 & 0.707 \\
\hline 11. I think eating sweet or salty snacks is not bad for my child & 0.135 & -0.276 & & 0.603 \\
\hline 12. My child is not allowed to snack while watching TV & & -0.324 & & -0.454 \\
\hline
\end{tabular}




\subsubsection{Parent/Carer Nutritional Knowledge for Snacks}

Questions that were related to parental nutritional knowledge were embedded in the CORE-Q. We used these to develop a measure of nutritional knowledge in relation to snack foods, by establishing a scoring system that was based on expert consensus. Our scoring system incorporated recommendations for both healthy and unhealthy snack foods, and quantified disparity from those recommendations, which allowed for a more nuanced and varied scale scoring than previously derived from this questionnaire [34]: moreover, our method is similar to one that has previously been shown to result in more general nutritional knowledge scores being predictive of children's eating behaviour [35]. A summary measure of parents' understanding of recommended healthy snacking patterns was derived from responses to a question "What do you think is an acceptable consumption of the following food items for 4-6 year-old children?" for each of 10 possible food categories. There were eight possible responses: never; on certain occasions i.e., birthdays; 1 or less times per week; $2-4$ times per week; 5-6 times per week; 1-2 times per day; 3-4 times per day; and, 5 or more times per day. The food categories were: sweets/candies/chocolate; biscuits/cookies/cakes/muffins; crisps and other similar salty snacks; fruit and vegetables; pizza, cheese pies/meat pies; milk (plain); yogurt (plain); milk (flavoured); yogurt (flavoured); and, cheese.

The present study interpreted recommendations for snack food consumption based upon the dietary recommendations of the Belgian Health Council, the World Health Organization, and the advice for school food standards for England [36], combined with data on habitual dietary intake in the Belgian population [37] since food-based dietary guidelines (FBDG) for preschool children only exist on a national basis. These FBDG are very similar to dietary guidelines in other countries [38], which makes these guidelines applicable for a European population of preschoolers [39].

On this basis, expert consensus was achieved (Toybox-study Group) on what frequencies of consumption would be recommended for each of these categories, for four to six year-old children, as shown in Table 2, with the exception of cheese for which no consensus was reached. For each category, recommendations encompassed two or three possible frequency responses. Subsequently, responses were recoded to indicate the closeness to the recommendations by giving a maximum score to responses equal to the recommendations, and then one point was subtracted for each frequency level by which the responses differed from recommendations. The maxima were set at either six or seven, depending on whether recommended frequencies spanned two or three levels, so that the minimum possible score for any category was one. For example, if a caregiver indicated that they believed that salty snacks were recommended to be eaten ' 1 or less times per week', i.e., one level above the nearest recommended frequency, they would be scored as $6-1=5$ for that response.

Table 2. Description of recommendations for frequency consumption of different snack food categories for preschool children.

\begin{tabular}{cc}
\hline Snack Food Category & Recommended Frequency of Consumption \\
\hline sweets/candies/chocolate & Never to 1 or less times per week \\
biscuits/cookies/cakes/muffins & Never to 'on certain occasions' \\
crisps and other similar salty snacks & Never to 'on certain occasions' \\
fruit and vegetables & $3-4$ times to 5 or more times per day \\
pizza, cheese pies/meat pies & 'On certain occasions' to '1 or less times per week' \\
milk (plain) & $1-2$ to 3-4 times per day \\
Yogurt (plain) & $1-2$ to 3-4 times per day \\
milk (flavoured) & Never to 1 or less times per week \\
yogurt (flavoured) & Never to 1 or less times per week \\
\hline
\end{tabular}

Note: Based on national guidelines and expert consensus from the ToyBox-study Group (see text for references).

These individual snack category knowledge scores were summed to provide an overall snack nutritional knowledge score. As this score was negatively skewed, the variable was reversed, then 
natural log transformed, and then unreversed to maintain the original score direction. This final transformed variable was normally distributed.

\subsubsection{Parent/Carer Snack Modelling Behaviour}

From the CORE-Q, the principal parental modelling variables were derived from parents' reports of frequency of consuming various snack foods, from a question asking "How often do you consume the following items as a snack (in between your main meals)?". The foods listed were: Nuts/peanuts; Cakes/muffins; Wholemeal Bread; Biscuits/cookies; Crisps and other similar salty snacks; Crackers, breadsticks; Chocolate; Sweets/candies; Cheese; Cheese pies/meat pies; Yogurt/fresh cheeses; Pizza; Fresh fruits; and, Vegetables.

Frequency categories were: never; 1 or less times per week; $2-4$ times per week; $5-6$ times per week; $1-2$ times per day; $3-4$ times per day; and, 5 or more times per day. The frequencies were recoded to times per day using mid-point frequencies as follows: $0 ; 0.143 ; 0.429 ; 0.786 ; 1.5 ; 3.5$; and, 5 .

These were used to form a total frequency per day of consuming healthy or unhealthy snack foods, by summing two groups of snack food categories, as follows: 'healthy snacks': nuts, wholemeal bread, yogurt, fruits, vegetables; 'unhealthy snacks': cakes, biscuits, salty snacks, chocolate, sweets, pies, and pizza. These variables were positively skewed and so were transformed by natural logarithm. The transformed variables were normally distributed.

A general parent snacking frequency variable was derived from questions asking "How often do you usually have something to eat as snack between the meals during weekdays, for morning, afternoon and evening snack", with frequency responses ranging from "never" (scored 0), then "On 1 day" up to "on 5 days". The same questions were asked about weekends but responses included "never", "On 1 day" and "On 2 days". The responses were summed to provide a score of overall frequencies of snacking per week. This variable was normally distributed (range 0 to 21, which is the full possible range).

\subsection{Anthropometry}

Two consecutive measurements of children's weight to the nearest $100 \mathrm{~g}$ while using electronic scales (types SECA 861 and SECA 813; Seca, Hamburg, Germany) and height to the nearest $0.1 \mathrm{~cm}$ using a portable stadiometer (types SECA 225 and SECA 214; Seca) were taken. For anthropometric measurements, the children were measured in light clothing without shoes, and were asked to stand still in an erect position. Body mass index (BMI; weight, $\mathrm{kg} /(\text { height, } \mathrm{m})^{2}$ ) z-scores (zBMI) were calculated with use of the LMS method and children were categorized as normal weight or overweight/obese [40]. Parental age, height, and weight were obtained by self-report on the CORE-Q. Parental BMI was positively skewed and so was transformed to a non-skewed distribution by natural logarithm prior to parametric statistical analyses.

Resting energy expenditure (REE) for the children (3-10 years old) was calculated while using the Schofield equation, including both height and weight, as recommended for such populations [41]. This enabled energy needs to be controlled for when, for example, relating child zBMI to snack intake variables.

\subsection{Dependent Variables}

\subsubsection{Child snack Intakes from Child Food Frequency Questionnaire}

Two variables were derived from the Child FFQ: first, daily intakes were estimated from the product of the frequency of consumption per day and the standard portion size for that food, as specified on the questionnaire. The intakes of likely snack foods were then grouped into 'healthy' and 'unhealthy' lists, as follows: Healthy snack foods: Plain yogurt; cheese; fresh fruit; raw vegetables; unsweetened cereals; wholemeal bread and similar bakery products. Unhealthy snack foods: chocolate; cakes; biscuits; pastries; sweet spreads; salty snacks; and, sugar-based desserts. 
Intakes within each group were summed to provide child healthy and unhealthy snack intake variables. The child unhealthy snack intake variable was positively skewed and so was transformed by a natural logarithm. The transformed variable was normally distributed.

\subsubsection{Child Snacking Tendencies}

An overall estimate of frequency of child snacking behaviour was derived from the question "How often does your child eat something in between meals?", with the response frequencies ranging from "never or less than once a month" to "every day". The responses were recoded into child snacking frequency per week. However, this variable was somewhat bipolar distributed; therefore, the variable was recoded to form a dichotomous categorical variable, where those children reported to snack either 5-6 days a week or every day were classified as 'snacking most days' (60.6\%), and the remaining children were classified as 'not snacking most days' (36.9\%; $2.5 \%$ missing).

\subsection{Alpha Level Adjustment}

Alpha level for statistical significance was set at 0.01 due to the large sample size and large number of tests examined.

\subsection{Data Analysis}

Simple correlations were tested with Pearson's $r$ and partial correlations $\left(r_{p}\right)$, with variables being transformed to normalise if needed. For adjusted models, multilevel modelling was employed to predict child snack intake, using nlme package [42] in $\mathrm{R}$ [43], as this acknowledges the hierarchical structure of the data and it is robust against missing values [44]. Two hierarchical models were built, modelling healthy and unhealthy child snack intake. For both models, a two-level hierarchical structure was utilized (i.e., country/child). To be precise, each child with information on child anthropometry, parental attitudes, knowledge, modelling behaviour, and educational status as predictors was nested within the country information. Allowing for intercepts to vary across countries significantly improved the model fit for predicting child healthy snack intake $\left(\chi^{2}(1)=275.43, p<0.001\right)$, and child unhealthy snack intake $\left(\chi^{2}(1)=60.20, p<0.001\right)$, thus justifying the use of multilevel analyses.

For each analysis, adding predictor variables one by one and comparing the current model with the previous one, to develop a final model, created multiple models with fixed effects. Chi-square $\left(\chi^{2}\right)$ test of change in log-likelihood with full maximum-likelihood estimation (ML) was used to compare a model fit of different models [45]. The list of relevant predictor variables for each model was decided prior to the analyses and no predictors were excluded from the model due to lack of significance in order to evaluate whether and how much each hypothesised variable predicted the relevant outcome. Once fixed effects were modelled, the existence of random effects was also evaluated.

\section{Results}

\subsection{Participants}

From the original sample of 7076 parent-child dyads, 5185 were available for analyses, which included parents reporting involvement in cooking for and feeding their child. Of this sample, 97\% of participating parent/caregivers were mothers, $2.4 \%$ were fathers, the remaining $0.6 \%$ being step-parents or classified as other; the parent/caregiver is referred to here as 'parent'. There were 2685 (51.8\%) boys and $2500(48.2 \%)$ girls. Table 3 provides descriptive data for the parents and children. 
Table 3. Descriptive statistics for participant characteristics.

\begin{tabular}{cccccc}
\hline & N & Mean & SD & Min. & Max. \\
\hline Child Age (years) & 5183 & 4.75 & 0.43 & 3.50 & 5.49 \\
Parent/Carer Age (years) & 5158 & 35.60 & 4.82 & 21 & 66 \\
Parent BMI & 5080 & 23.49 & 4.14 & 15.23 & 60.24 \\
Child zBMI & 5000 & 0.22 & 1.03 & -5.87 & 4.01 \\
Child healthy snack intake (g/d) & 5156 & 256.1 & 139.7 & 0.0 & 842.9 \\
Child unhealthy snack intake (g/d) & 5149 & 57.3 & 42.4 & 0.0 & 374.6 \\
Child resting energy expenditure (kcal/d) & 5000 & 883.65 & 61.66 & 701.06 & 1276.50 \\
\hline
\end{tabular}

\subsection{Differences in Child zBMI and Snack Consumption by Country}

Child zBMI significantly varied across the six countries (Table 4: one-way ANOVA, country effect, $\mathrm{F}(5,4994)=18.1, p<0.001)$, with the most marked difference being that zBMI for Greece was higher than all other countries.

Table 4. Differences by country in child zBMI and measures of healthy and unhealthy snack consumption, and the ratio of healthy to unhealthy snack intake. Data are expressed as means (95\% CIs).

\begin{tabular}{|c|c|c|c|c|c|c|}
\hline Country & N Range ${ }^{1}$ & Child zBMI & $\begin{array}{c}\text { Snacks Per } \\
\text { Week }\end{array}$ & $\begin{array}{c}\text { Healthy Snack } \\
\text { Intake }^{2}(\mathrm{~g} / \mathrm{d})\end{array}$ & $\begin{array}{l}\text { Unhealthy Snack } \\
\text { Intake }^{2}(\mathrm{~g} / \mathrm{d})\end{array}$ & $\begin{array}{c}\text { Healthy: } \\
\text { Unhealthy Snack } \\
\text { Ratio }^{3}\end{array}$ \\
\hline Belgium & $692-700$ & $\begin{array}{l}0.22^{\mathrm{a}} \\
(0.15-0.29)\end{array}$ & $\begin{array}{l}6.11^{\mathrm{a}} \\
(5.99-6.23)\end{array}$ & $\begin{array}{l}219.5^{\mathrm{a}} \\
(209.3-229.6)\end{array}$ & $\begin{array}{l}67.1^{\mathrm{a}} \\
(63.9-70.3)\end{array}$ & $\begin{array}{l}4.24^{\mathrm{a}} \\
(3.97-4.51)\end{array}$ \\
\hline Bulgaria & $580-606$ & $\begin{array}{l}0.24^{\mathrm{a}} \\
(0.16-0.32)\end{array}$ & $\begin{array}{l}5.13^{b c} \\
(4.95-5.30)\end{array}$ & $\begin{array}{l}328.9^{\mathrm{b}} \\
(318.0-339.8)\end{array}$ & $\begin{array}{l}64.2^{\mathrm{b}} \\
(60.7-67.6)\end{array}$ & $\begin{array}{l}10.26^{\mathrm{b}} \\
(8.56-11.96)\end{array}$ \\
\hline Greece & $1258-1306$ & $\begin{array}{l}0.43^{\mathrm{c}} \\
(0.37-0.49)\end{array}$ & $\begin{array}{l}5.43^{\mathrm{b}} \\
(5.31-5.55)\end{array}$ & $\begin{array}{l}248.3^{d} \\
(240.8-255.8)\end{array}$ & $\begin{array}{l}56.9^{c} \\
(54.5-59.3)\end{array}$ & $\begin{array}{l}8.60 \text { bc } \\
(7.60-9.59)\end{array}$ \\
\hline Poland & 1055-1065 & $\begin{array}{l}0.10^{\mathrm{ab}} \\
(0.04-0.16)\end{array}$ & $\begin{array}{l}4.81^{\mathrm{c}} \\
(4.69-4.95)\end{array}$ & $\begin{array}{l}248.2^{\mathrm{d}} \\
(240.1-256.2)\end{array}$ & $\begin{array}{l}55.4^{\mathrm{c}} \\
(52.9-58.0)\end{array}$ & $\begin{array}{l}8.64^{\mathrm{bc}} \\
(7.47-9.81)\end{array}$ \\
\hline
\end{tabular}

\footnotetext{
${ }^{1}$ Sample sizes varied slightly for complete data for each measure within countries. ${ }^{2}$ Estimated marginal means adjusted for child resting energy expenditure as a significant covariate. For unhealthy snack intake, analyses were performed on Ln-transformed data. ${ }^{3}$ Healthy snack intake divided by unhealthy snack intake, excluding zero values for either variable; a higher number represents a healthier snacking profile. ${ }^{\text {abcd }}$ Differing superscript letters within each column indicate significant differences between countries (Bonferroni multiple comparisons).
}

For frequency of snacks per week, Belgium showed the highest, whereas Spain showed the lowest frequency when compared to the other countries (Table 4: one-way ANOVA, country effect, $\mathrm{F}(5,5052)$ $=271.2, p<0.001$; REE was not a significant covariate for snacking frequency in ANCOVA).

Healthy and unhealthy snack intakes also varied by country but contrasted with differences in snacking frequency. For healthy snack intake, Belgium and Spain showed the lowest intakes, and Bulgaria the highest (Table 4: adjusted for child REE, ANCOVA country effect, $\mathrm{F}(5,4965)=63.9$, $p<0.001$; REE covariate, $\mathrm{F}(1,4965)=33.4, p<0.001)$. For unhealthy snack intake, Belgium was notably higher than all other countries (ANCOVA on Ln-transformed data adjusted for REE, country effect, $\mathrm{F}(5$, $4957)=20.9, p<0.001$; REE covariate, $\mathrm{F}(1,4965)=4.01, p<0.05)$. We also report the ratio of healthy to unhealthy snack intake, since this provides an indicator of the healthiness of snacking behaviour, independent of overall snack intake: this again varied across countries, with Belgium having the least healthy profile (lowest ratio) as compared to other countries, although not significantly different from the next lowest, Spain (Table 4: one-way ANOVA, country effect, $\mathrm{F}(5,5091)=11.2, p<0.001$ ). 


\subsection{Is Parental Snacking Behaviour Associated with Child Healthy and Unhealthy Snacking?}

The overall estimate of parent's weekly snacking frequency was unrelated to child healthy snack intake, but it was associated with greater child unhealthy snack intake (Table 5). Parents' healthy snacking frequency was associated with greater child healthy, but not unhealthy, snack intake. Conversely, parents' unhealthy snacking frequency was associated with greater unhealthy, but not healthy, child snack intake.

Table 5. Correlations (Pearson's r) between parent snacking practices and child snacking behaviour.

\begin{tabular}{|c|c|c|}
\hline Parental Predictor Variables & Child Healthy Snack Intake a & Child Unhealthy Snack Intake ${ }^{b}$ \\
\hline Parent healthy snacks/day & $0.204 * *$ & -0.014 \\
\hline Parent unhealthy snacks/day & -0.009 & $0.255 * *$ \\
\hline Parent snacks/week & 0.008 & $0.121 * *$ \\
\hline Healthy snack provision & $0.115 * *$ & 0.018 \\
\hline Permissive healthy snacking & $0.075 * *$ & 0.006 \\
\hline Unhealthy snacks child responsive & $-0.150 *$ & $0.157 * *$ \\
\hline Permissive unhealthy snacking & $-0.136 * *$ & $0.249 * *$ \\
\hline Knowledge of snack recommendations & $0.166 * *$ & $-0.210 * *$ \\
\hline
\end{tabular}

Furthermore, children who snacked on most days of the week had parents who snacked more often $(n=3193$, mean $[S D]=11.04$ [5.52] times per week) than did children who did not snack on most days of the week $(n=1798$, mean [SD] $=8.37$ [5.29] times per week), $\mathrm{t}(3861.3)=16.89 p<0.001$; adjusted for unequal variances, Levene's $\mathrm{F}=6.80, p=0.009$ ).

\subsection{Are Parental Attitudes and Practices Concerning Snacking Associated with Child Healthy and Unhealthy} Snack Intakes?

Providing healthy snacks, and being permissive about allowing healthy snacking were both associated with greater child healthy snack intake, but not with child unhealthy snack intake. Conversely, allowing for unhealthy snacking was strongly associated with greater child unhealthy snack intake, but negatively related to healthy snack intake (Table 5). Similarly, responding to child demands for unhealthy snacks was associated with higher unhealthy snack consumption and less healthy snack consumption by their children.

Greater parent/caregiver understanding of recommendations for snack food consumption for young children was associated with more child healthy snack intake and less child unhealthy snack intake. Moreover, parents with more years of education also had greater knowledge regarding snack recommendations (Pearson's $\mathrm{r}(5030)=0.126, p<0.001$ ).

These associations, although cross-sectional, suggest that parental snacking behaviour and practices may be influencing both child healthy and unhealthy snack consumption.

\subsection{Associations between Snacking Behaviours and Child Obesity}

In zero-order correlations, child zBMI was positively associated with children's reported intake of healthy snacks $(\mathrm{r}(4972)=0.051, p<0.001)$, but unrelated to unhealthy snack intake $(\mathrm{r}(4964)=0.007$, $p=0.612)$. More parental years of education was associated with higher child healthy snack intake $(\mathrm{r}(5050)=0.081, p<0.001)$ and lower unhealthy snack intake $(\mathrm{r}(5042)=-0.042, p=0.003)$, and with lower child zBMI $(\mathrm{r}(4895)=-0.071, p<0.001)$.

However, because zBMI is strongly related to REE $(\mathrm{r}(5000)=0.667, p<0.001)$, which in turn could drive snack intake, partial correlations were used to control for any influence of REE. zBMI was no longer associated with either healthy $\left(r_{p}(4953)=-0.005, p=0.699\right)$ or unhealthy $\left(r_{p}(4953)=0.000\right.$, $p=0.994)$ snack intake with these adjusted partial correlations.

In line with this lack of relationship between zBMI and child snacking, only one significant relationship for snacking attitudes and practices of parents was seen with child zBMI among these 
partial correlations: children with higher zBMI had parents who tended to report being less permissive regarding healthy snacking by their child $\left(\mathrm{r}_{\mathrm{p}}(4819)=-0.060, p<0.001\right)$. Knowledge of snack recommendations was weakly positively related to zBMI in these adjusted analyses $\left(r_{p}=0.029\right.$, $p=0.041$ ), although not significantly at $p<0.01$. Neither permissiveness nor responsiveness for unhealthy snacking, nor provisioning for healthy snacking, were related to zBMI in these partial correlations (respectively, $\mathrm{r}_{\mathrm{p}}=0.011,0.001,0.008$ ).

\subsection{Hierarchical Multilevel Modelling of Predictors of Child Snack Intake}

Hierarchical linear regression, or multilevel modelling is the more powerful method for testing for adjusted associations in these hierarchical data. These models adjust for any potentially significant variance due to differences between kindergartens or countries; in this case, the best model used two levels, child nested in country. Tables 6 and 7 present these regression results for predictors of child healthy and unhealthy snack intake, respectively.

Table 6. Hierarchical linear regression statistics for predictors of child healthy snack intake.

\begin{tabular}{cccc}
\hline Predictor & B (SE) & $\mathbf{t ( 4 7 0 0 )}$ & Predictive $p$ Value \\
\hline Child zBMI & $1.43(2.48)$ & 0.58 & 0.565 \\
Resting energy expenditure & $0.18(0.04)$ & 4.24 & $<0.0001$ \\
Parent unhealthy snack intake & $3.30(1.32)$ & 2.50 & 0.013 \\
Parent healthy snack intake & $5.23(0.59)$ & 8.84 & $<0.0001$ \\
Parent snacking frequency & $0.82(0.37)$ & 2.25 & 0.025 \\
Knowledge of recommendations & $32.99(4.05)$ & 8.14 & $<0.0001$ \\
Unhealthy snack permissiveness & $-17.43(3.17)$ & 5.50 & $<0.0001$ \\
Unhealthy snack responsiveness & $-16.21(2.64)$ & 6.15 & $<0.0001$ \\
Healthy snack permissiveness & $-0.83(1.97)$ & 0.42 & 0.675 \\
Healthy snack provision & $28.50(3.06)$ & 9.33 & $<0.0001$ \\
Parent/carer education level & $7.42(1.70)$ & 4.35 & $<0.0001$ \\
\hline
\end{tabular}

Note: The multilevel model accounts for variance at the levels of child (1) and country (2). Child zBMI was a significant fit in the model ( $\log$ Likelihood Ratio $=18.30, p<0.0001)$ but not a significant multilevel predictor of child healthy snack intake. Sex and SES were not related to the dependent variable in this model. Strongest predictors shown in bold.

Table 7. Hierarchical linear regression statistics for predictors of child unhealthy snack intake.

\begin{tabular}{cccc}
\hline Predictor & B (SE) & $\mathbf{t}(\mathbf{4 6 9 3 )}$ & Predictive $\boldsymbol{p}$ Value \\
\hline Child zBMI & $-0.62(0.77)$ & 0.80 & 0.423 \\
Resting energy expenditure & $0.03(0.02)$ & 2.55 & 0.011 \\
Parent unhealthy snack intake & $4.90(0.41)$ & 11.83 & $<0.0001$ \\
Parent healthy snack intake & $0.10(0.18)$ & 0.53 & 0.593 \\
Parent snacking frequency & $0.15(0.11)$ & 1.34 & 0.180 \\
Knowledge of recommendations & $-10.91(1.26)$ & 8.64 & $<0.0001$ \\
Unhealthy snack permissiveness & $8.65(0.98)$ & 8.85 & $<0.0001$ \\
Unhealthy snack responsiveness & $4.90(0.82)$ & 5.98 & $<0.0001$ \\
Healthy snack permissiveness & $1.54(0.61)$ & 2.53 & 0.012 \\
Healthy snack provision & $0.89(0.94)$ & 0.95 & 0.341 \\
Parent/carer education level & $-1.64(0.53)$ & 3.10 & 0.002 \\
\hline
\end{tabular}

Note: The multilevel model accounts for variance at the levels of child (1) and country (2). Sex and SES were not related to the dependent variable. Strongest predictors shown in bold.

In addition to REE, which was a strong predictor, child healthy snack intake was independently associated with having parents who had more years of education, had better knowledge of snack recommendations, ate more healthy snacks, provided more healthy snacks to their children, and were more restrictive of unhealthy snack consumption (Table 6). Child zBMI was unrelated to healthy snack intake. 
In contrast, for child unhealthy snack intake, REE was relatively weakly positively related, implying mainly non-regulatory (e.g., hedonic) drivers to eat such snacks (Table 7). Children who ate more unhealthy snacks had parent/carers who ate more unhealthy snacks, were less restrictive of their children eating such snacks, had fewer years of education, and were less knowledgeable about snack recommendations. Child unhealthy snack intake was also unrelated to parents' healthy snacking, implying a specific association to the class of snack.

\section{Discussion}

This study has applied some novel behavioural measures of parental attitudes, as well as their own snacking behaviour, to both healthy and unhealthy child snacking behaviour, in a cross-sectional analysis of a large and well-measured sample of 3.5-5.5 year-old children. The findings contribute to the limited existing literature on this topic [30], and they provide some useful and novel understandings of the differential influences of parental behaviour on healthy and unhealthy snacking by their children, and implications for obesity risk in young children.

There was clear evidence that parental habitual snacking was associated with, and likely influenced, their child's snacking: thus, for the specific parental snack frequency variables, parental healthy and unhealthy snack intake predicted respective child healthy and unhealthy snack intake, but not vice-versa. Furthermore, children who snacked on most days had parents who reported snacking more frequently than did the parents of children who did not snack on most days. These associations could reflect the child acquiring snacking habits through parental modelling of snacking, although other mechanisms could be involved, including exposure and opportunity via snack availability in the home. Our data do not allow for us to distinguish these possibilities for certain, although the parent/carer was specifically the main feeder of their child here, parent/carer snack intake was predictive of child snack intake independently of a measure of snack provision, and parental modelling has been shown to promote both snacking [46,47] and fruit and vegetable consumption [35,48,49].

The parental feeding strategies for young children are known to result in differential effects on the healthiness of their children's diets [50,51]. Here, being permissive about their child's snacking promoted only unhealthy snack intake, whereas children's healthy snack intake was higher in parents who were specifically less permissive of, or less responsive to, unhealthy snacking. It is possible that the more hedonically attractive, and energy-dense, nature of unhealthy snacks makes them more amenable to such parental strategies or simple modelling effects than might be the case for healthier snacks, at least in young children [52,53]. A key variable that was not directly assessed here might be expressed preference as opposed to just intake, as in another study maternal food preferences were an important predictor of children's intake of healthy foods but not unhealthy foods [53]. Nevertheless, in this study, healthy snack provision did appear to promote specifically healthy snack intake, independent of parental intake, nutritional knowledge, or education. It should also be noted that these results are independent of country differences, as this level was controlled for in the multilevel modelling. Nevertheless, we replicated the earlier report from ToyBox-study data that Belgium children appear to most frequently snack [24], and extend this to show that their snacking profile was the least healthy of the six countries. Presumably, the country differences in snacking reflect a combination of cultural, economic, environmental, and food availability influences.

To summarise, beyond potential modelling effects from eating snacks (to the extent to which this happened in the child's presence), our findings from the measures representing parental snack feeding practices were also significantly associated with the children's healthy and unhealthy snack consumption. On the positive side, parents' practices of making healthy snacks available to their children was associated with greater child healthy snack intake, but it did not relate to unhealthy snack intake. Conversely, parental practices that are related to unhealthy snacking, i.e., being permissive about unhealthy snacking including making them available, and being responsive or acceding to child demands for unhealthy snacks, was associated with the greater consumption of unhealthy snacks by children, but also less intake of healthy snacks. This suggests that when unhealthy snacking is 
encouraged, their intake displaces healthy snacks from children's diet, although the reverse might not be the case.

In addition to these parental practices regarding their children's snacking, parents having greater nutritional knowledge of snack food recommendations had children who ate more healthy snacks and fewer unhealthy snacks. This measure was a strong predictor of child healthy vs. unhealthy snacking, independent of education level: thus, this finding supports the use of nutritional education for parents as an aspect of interventions addressing children's diets and obesity risk [34]. The weak tendency for higher child zBMI to be associated with greater parental nutritional knowledge was an unexpected finding: if not a chance result, it could perhaps indicate some reverse causality, i.e., greater interest in dietary recommendations among parents with more overweight children.

The associations between parental snacking practices and their children's snacking shows that such parenting techniques are significant influences on healthy and unhealthy snacking in these young children: thus, practitioners should educate parents regarding the importance of their own behaviours, as well as instilling knowledge of snack food group recommendations, whilst being aware that less educated parents are particularly at risk of unhealthy parental practices [54,55]. Furthermore, such advice is supported by evidence that interventions, such as the ToyBox-study, can improve relevant parental snacking practices and rule-setting, as well as nutritional knowledge of parents [34]. However, there was little support here for associations between child snacking and child obesity, which is in agreement with a previous analysis of associations between unhealthy snacking and baseline BMI in these children, although soft drink consumption, which was not examined here, was found to be positively related to BMI [56]. One reason might be that this age range is approaching the age (5-6 years old) at which BMI typically reaches a minimum ('adiposity rebound'), thus limiting the variance in BMI, before rising again through to adulthood. The limited associations between either child snacking or parental snacking practices and child obesity are also consistent with other studies of parental and child snacking behaviours and obesity in similar aged young children [22,30]. Still, children starting the adiposity rebound at a younger age are much more likely to be obese in adulthood [57], so preschool child overweight or obesity is still a concern; furthermore, child obesity dramatically increases during early school years, and unhealthy energy-dense snacking is likely to be a contributory factor [12]. Moreover, we did find evidence that parents who were less permissive in encouraging healthy snacking had children with higher zBMI; this might indicate that healthy snacks, which are generally lower in energy density than unhealthy snacks, could help displace unhealthy snacks and so reduce the children's overall energy intake.

With this in mind, particularly from a research perspective, an innovation in this study was to include REE as a predictor alongside BMI, in an attempt to separate the impact that greater energy needs per se might have on snack intake from other behavioural characteristics that may be inherently linked to being a heavier child. For instance, snacking, especially as defined by eating energy-dense food between meals, has been considered to be an expression of 'eating in the absence of hunger', which has been associated with an increased adiposity in young children $[8,58]$, perhaps due to weaker appetite regulation in more overweight children [59], which in turn could result from parental use of controlling feeding practices [60]. However, the inclusion of REE in the regression analyses resulted in REE, but not zBMI being a significant predictor of both healthy and unhealthy snack intake in our fully adjusted multilevel models. It should also be noted that, despite zBMI being greater in Greece than the other intervention countries, as was previously observed [61], our hierarchical analyses controlled for such country-level variation. Furthermore, although sex differences in the associations between fruit and vegetable intake and child obesity have been reported for this ToyBox-Study cohort (albeit a smaller sample) [56], we did not find an effect of sex on healthy or unhealthy child snack intake in our multilevel models, including REE. Therefore, investigators should consider controlling for differences in physiological energy requirements that vary with body mass, age, and sex when examining relationships between children's snack intake, obesity and potential behavioural risk factors; then, for example, any associations between snacking-related behaviours and child obesity 
would not be confounded by greater energy needs in more overweight or at least heavier, older, or faster-growing children.

This study is limited by the self-report nature of the behavioural variables, and the development of new measures without full psychometric validation. A further limitation of our observations is that the effect sizes were generally moderate to very small, and the associations cross-sectional: thus, it must be acknowledged that other factors, some of which may covary with snacking, which have not been addressed here, could play more important roles in linking parental and child behaviour to child obesity risk $[62,63]$. It is also possible that unhealthy snacking has not yet had time to influence the development of obesity in these young children; however, we only examined cross-sectional relationships at baseline in order to benefit from the largest sample size.

One factor not measured here that could disrupt simple associations between overweight and obesity, healthy or unhealthy snacking, parental practices, and indeed fruit and vegetable intake, is the children's fussy eating tendencies, since fussy eaters will tend to avoid snacking on healthy foods, yet also tend to be thinner $[64,65]$. In fact, parents often struggle to find successful strategies for promoting healthy eating in picky/fussy children [66]. Moreover, it is likely that associations between energy-dense snack consumption and obesity will increase with age of the child [56,58].

\section{Conclusions}

Child obesity was unrelated to their (healthy or unhealthy) snack intake, in adjusted models that included energy requirements, parental education, and feeding practices, perhaps reflecting the young age of the children and the greater importance of parental influences. Clear independent predictors of both healthy and unhealthy snacking included knowledge of dietary recommendations for snack foods (negative for unhealthy snacking), parent/carer education, and parent/carer snack intake. Unhealthy snacking can lead to dietary habits that are harmful to health, irrespective of obesity, and these findings could help to support interventions for improving children's nutritional status, as well as the dissemination of healthy dietary practices to parents of young children.

Author Contributions: Study conceptualisation, E.L.G., G.C., I.D.B., B.K., Y.M. and O.A.; Methodology, E.L.G., L.M., P.F.-B., P.S., V.I., G.C., I.D.B., B.K., Y.M. and O.A.; Formal Analysis, E.L.G. and S.S.; Investigation and data collection, all authors; Data Curation, E.L.G., L.M., S.S., Y.M. and O.A.; Writing-Original Draft Preparation, E.L.G., V.I., G.C., I.D.B., B.K., and O.A.; Writing-Review \& Editing, E.L.G., L.M., P.F.-B., V.I., G.C., I.D.B., B.K., S.S., Y.M. and O.A.; Visualization, E.L.G.; Supervision, Y.M. and O.A.; Project Administration, Y.M. and O.A.; Resources, Y.M., I.D.B., B.K., L.M., V.I. and P.S.; Funding Acquisition, Y.M., I.D.B., B.K., L.M., V.I., and P.S. All authors revised the manuscript for important intellectual content, read and approved the final manuscript. All authors have read and agreed to the published version of the manuscript.

Funding: The ToyBox study was funded by the Seventh Framework Programme (CORDIS FP7) of the European Commission under grant agreement no. 245200. The content of this article reflects only the authors' views and the European Community is not liable for any use that may be made of the information contained therein. Funding from this grant is not available to cover APC fees.

Acknowledgments: The authors would like to thank the members of the ToyBox study group: Coordinator: Y.M.; Project manager: O.A.; Steering Committee: Y.M., B.K., I.D.B., Mai Chin A Paw, L.M., Carolyn Summerbell, Tim Lobstein, Lieven Annemans, Goof Buijs; External Advisors: John Reilly, Boyd Swinburn, Dianne Ward; Harokopio University (Greece): Y.M., O.A., Eva Grammatikaki, Christina Katsarou, Eftychia Apostolidou, Anastasia Livaniou, Eirini Efstathopoulou, Paraskevi- Eirini Siatitsa, Angeliki Giannopoulou, Effie Argyri, Konstantina Maragkopoulou, Athanasios Douligeris, Roula Koutsi; Ludwig Maximilians Universitaet Muenchen (Germany): B.K., Kristin Duvinage, Sabine Ibrügger, Angelika Strauß, Birgit Herbert, Julia Birnbaum, Annette Payr, Christine Geyer; Ghent University (Belgium): Department of Movement and Sports Sciences: I.D.B., Greet Cardon, Marieke De Craemer, Ellen De Decker; Department of Public Health: Lieven Annemans, Stefaan De Henauw, Lea Maes, Carine Vereecken, Jo Van Assche, Lore Pil; VU University Medical Center EMGO Institute for Health and Care Research (The Netherlands): EMGO Institute for Health and Care Research: Mai Chin A Paw, Saskia te Velde; University of Zaragoza (Spain): L.M., Theodora Mouratidou, Juan Fernandez, Maribel Mesana, Pilar De Miguel-Etayo, Esther M. González-Gil, Luis Gracia-Marco, Beatriz Oves, Paloma Flores Barran; Oslo and Akershus University College of Applied Sciences (Norway): Agneta Yngve, Susanna Kugelberg, Christel Lynch, Annhild Mosdøl, Bente B. Nilsen; University of Durham (UK): Carolyn Summerbell, Helen Moore, Wayne Douthwaite, Catherine Nixon; State Institute of Early Childhood Research (Germany): Susanne Kreichauf, Andreas Wildgruber; Children's Memorial Health Institute (Poland): Piotr Socha, Zbigniew Kulaga, Kamila Zych, Magdalena Góźdź, Beata Gurzkowska, Katarzyna Szott; Medical University of Varna (Bulgaria): Violeta Iotova, Mina Lateva, Natalya Usheva, Sonya 
Galcheva, Vanya Marinova, Zhaneta Radkova, Nevyana Feschieva; International Association for the Study of Obesity (UK): Tim Lobstein, Andrea Aikenhead; CBO B.V. (the Netherlands): Goof Buijs, Annemiek Dorgelo, Aviva Nethe, Jan Jansen; AOK-Verlag (Germany): Otto Gmeiner, Jutta Retterath, Julia Wildeis, Axel Günthersberger; Roehampton University (UK): Leigh Gibson; University of Luxembourg (Luxembourg): Claus Voegele.

Conflicts of Interest: The authors declare no conflict of interest.

\section{References}

1. World Health Organisation. Report of the Commission on Ending Childhood Obesity; World Health Organisation: Geneva, Switzerland, 2016.

2. Colquitt, J.L.; Loveman, E.; O’Malley, C.; Azevedo, L.B.; Mead, E.; Al-Khudairy, L.; Ells, L.J.; Metzendorf, M.I.; Rees, K. Diet, physical activity, and behavioural interventions for the treatment of overweight or obesity in preschool children up to the age of 6 years. Cochrane Database Syst. Rev. 2016, 3. [CrossRef] [PubMed]

3. Gibson, E.L.; Kreichauf, S.; Wildgruber, A.; Vogele, C.; Summerbell, C.D.; Nixon, C.; Moore, H.; Douthwaite, W.; Manios, Y.; ToyBox-Study Group. A narrative review of psychological and educational strategies applied to young children's eating behaviours aimed at reducing obesity risk. Obes. Rev. 2012, 13 (Suppl. 1), 85-95. [CrossRef] [PubMed]

4. Waters, E.; de Silva-Sanigorski, A.; Hall, B.J.; Brown, T.; Campbell, K.J.; Gao, Y.; Armstrong, R.; Prosser, L.; Summerbell, C.D. Interventions for preventing obesity in children. Cochrane Database Syst. Rev. 2011. [CrossRef] [PubMed]

5. Savage, J.S.; Fisher, J.O.; Birch, L.L. Parental influence on eating behavior: Conception to adolescence. J. Law Med. Ethics 2007, 35, 22-34. [CrossRef]

6. Birch, L.L.; Ventura, A.K. Preventing childhood obesity: What works? Int. J. Obes. 2009, 33, S74-S81. [CrossRef]

7. Wang, Z. High ratio of resting energy expenditure to body mass in childhood and adolescence: A mechanistic model. Am. J. Hum. Biol. 2012, 24, 460-467. [CrossRef]

8. Bellisle, F. Meals and snacking, diet quality and energy balance. Physiol. Behav. 2014, 134, 38-43. [CrossRef]

9. Gibson, E.L.; Wardle, J. Energy density predicts preferences for fruit and vegetables in 4-year-old children. Appetite 2003, 41, 97-98. [CrossRef]

10. Wang, D.; van der Horst, K.; Jacquier, E.F.; Afeiche, M.C.; Eldridge, A.L. Snacking patterns in children: A comparison between Australia, China, Mexico, and the US. Nutrients 2018, 10. [CrossRef]

11. Dunford, E.K.; Popkin, B.M. 37 year snacking trends for US children 1977-2014. Pediatr. Obes. 2018, 13, 247-255. [CrossRef]

12. Public Health England. PHE Launches Change4Life Campaign around Children's Snacking. Available online: https://www.gov.uk/government/news/phe-launches-change4life-campaign-around-childrenssnacking (accessed on 9 March 2018).

13. Yee, A.Z.; Lwin, M.O.; Ho, S.S. The influence of parental practices on child promotive and preventive food consumption behaviors: A systematic review and meta-analysis. Int. J. Behav. Nutr. Phys. Act. 2017, 14, 47. [CrossRef] [PubMed]

14. Corsini, N.; Kettler, L.; Danthiir, V.; Wilson, C. Parental feeding practices to manage snack food intake: Associations with energy intake regulation in young children. Appetite 2018, 123, 233-240. [CrossRef] [PubMed]

15. Davison, K.K.; Blake, C.E.; Blaine, R.E.; Younginer, N.A.; Orloski, A.; Hamtil, H.A.; Ganter, C.; Bruton, Y.P.; Vaughn, A.E.; Fisher, J.O. Parenting around child snacking: Development of a theoretically-guided, empirically informed conceptual model. Int. J. Behav. Nutr. Phys. Act. 2015, 12, 109. [CrossRef] [PubMed]

16. Kral, T.V.E.; Chittams, J.; Moore, R.H. Relationship between food insecurity, child weight status, and parent-reported child eating and snacking behaviors. J. Spec. Pediatr. Nurs. 2017, 22. [CrossRef] [PubMed]

17. Blaine, R.E.; Kachurak, A.; Davison, K.K.; Klabunde, R.; Fisher, J.O. Food parenting and child snacking: A systematic review. Int. J. Behav. Nutr. Phys. Act. 2017, 14, 146. [CrossRef]

18. Webber, L.; Cooke, L.; Hill, C.; Wardle, J. Child adiposity and maternal feeding practices: A longitudinal analysis. Am. J. Clin. Nutr. 2011, 92, 1423-1428. [CrossRef] 
19. Webber, L.; Hill, C.; Cooke, L.; Carnell, S.; Wardle, J. Associations between child weight and maternal feeding styles are mediated by maternal perceptions and concerns. Eur. J. Clin. Nutr. 2010, 64, 259-265. [CrossRef]

20. Fildes, A.; van Jaarsveld, C.H.; Llewellyn, C.H.; Fisher, A.; Cooke, L.; Wardle, J. Nature and nurture in children's food preferences. Am. J. Clin. Nutr. 2014, 99, 911-917. [CrossRef]

21. Manios, Y.; Grammatikaki, E.; Androutsos, O.; Chinapaw, M.J.; Gibson, E.L.; Buijs, G.; Iotova, V.; Socha, P.; Annemans, L.; Wildgruber, A.; et al. A systematic approach for the development of a kindergarten-based intervention for the prevention of obesity in preschool age children: The ToyBox-study. Obes. Rev. 2012, 13 (Suppl. 1), 3-12. [CrossRef]

22. Corsini, N.; Wilson, C.; Kettler, L.; Danthiir, V. Development and preliminary validation of the Toddler Snack Food Feeding Questionnaire. Appetite 2010, 54, 570-578. [CrossRef]

23. Gevers, D.W.M.; Kremers, S.P.J.; de Vries, N.K.; van Assema, P. The Comprehensive Snack Parenting Questionnaire (CSPQ): Development and test-retest reliability. Int. J. Environ. Res. Public Health 2018, 15, 862. [CrossRef] [PubMed]

24. De Craemer, M.; Lateva, M.; Iotova, V.; De Decker, E.; Verloigne, M.; De Bourdeaudhuij, I.; Androutsos, O.; Socha, P.; Kulaga, Z.; Moreno, L.; et al. Differences in energy balance-related behaviours in European preschool children: The ToyBox-study. PLoS ONE 2015, 10, e0118303. [CrossRef] [PubMed]

25. Manios, Y.; Androutsos, O.; Katsarou, C.; Iotova, V.; Socha, P.; Geyer, C.; Moreno, L.; Koletzko, B.; De Bourdeaudhuij, I.; ToyBox-study Group. Designing and implementing a kindergarten-based, family-involved intervention to prevent obesity in early childhood: The ToyBox-study. Obes. Rev. 2014, 15 (Suppl. 3), 5-13. [CrossRef] [PubMed]

26. Gonzalez-Gil, E.M.; Mouratidou, T.; Cardon, G.; Androutsos, O.; De Bourdeaudhuij, I.; Gozdz, M.; Usheva, N.; Birnbaum, J.; Manios, Y.; Moreno, L.A.; et al. Reliability of primary caregivers reports on lifestyle behaviours of European pre-school children: The ToyBox-study. Obes. Rev. 2014, 15 (Suppl. 3), 61-66. [CrossRef] [PubMed]

27. Mouratidou, T.; Mesana Graffe, M.I.; Huybrechts, I.; De Decker, E.; De Craemer, M.; Androutsos, O.; Manios, Y.; Galcheva, S.; Lateva, M.; Gurzkowska, B.; et al. Reproducibility and relative validity of a semiquantitative food frequency questionnaire in European preschoolers: The ToyBox study. Nutrition 2019, 65, 60-67. [CrossRef] [PubMed]

28. Huybrechts, I.; De Backer, G.; De Bacquer, D.; Maes, L.; De Henauw, S. Relative validity and reproducibility of a food-frequency questionnaire for estimating food intakes among Flemish preschoolers. Int. J. Environ. Res. Public Health 2009, 6, 382-399. [CrossRef]

29. Mouratidou, T.; Miguel, M.L.; Androutsos, O.; Manios, Y.; De Bourdeaudhuij, I.; Cardon, G.; Kulaga, Z.; Socha, P.; Galcheva, S.; Iotova, V.; et al. Tools, harmonization and standardization procedures of the impact and outcome evaluation indices obtained during a kindergarten-based, family-involved intervention to prevent obesity in early childhood: The ToyBox-study. Obes. Rev. 2014, 15 (Suppl. 3), 53-60. [CrossRef]

30. Davison, K.K.; Blake, C.E.; Kachurak, A.; Lumeng, J.C.; Coffman, D.L.; Miller, A.L.; Hughes, S.O.; Power, T.G.; Vaughn, A.F.; Blaine, R.E.; et al. Development and preliminary validation of the Parenting around SNAcking Questionnaire (P-SNAQ). Appetite 2018, 125, 323-332. [CrossRef]

31. Rammstedt, B.; Beierlein, C. Can't We Make It Any Shorter? The limits of personality assessment and ways to overcome them. J. Individ. Differ. 2014, 35, 212-220. [CrossRef]

32. Sijtsma, K. On the Use, the Misuse, and the Very Limited Usefulness of Cronbach's Alpha. Psychometrika 2009, 74, 107-120. [CrossRef]

33. Guttman, L. A basis for analyzing test-retest reliability. Psychometrika 1945, 10, 255-282. [CrossRef] [PubMed]

34. Lambrinou, C.P.; van Stralen, M.M.; Androutsos, O.; Cardon, G.; De Craemer, M.; Iotova, V.; Socha, P.; Koletzko, B.; Moreno, L.A.; Manios, Y. Mediators of the effectiveness of a kindergarten-based, family-involved intervention on pre-schoolers' snacking behaviour: The ToyBox-study. Public Health Nutr. 2019, 22, 157-163. [CrossRef] [PubMed]

35. Gibson, E.L.; Wardle, J.; Watts, C.J. Fruit and vegetable consumption, nutritional knowledge and beliefs in mothers and children. Appetite 1998, 31, 205-228. [CrossRef] [PubMed]

36. Department for Education, England. Standards for school food in England. Available online: https://www. gov.uk/government/publications/standards-for-school-food-in-england (accessed on 12 December 2017). 
37. De Keyzer, W.; Lin, Y.; Vereecken, C.; Maes, L.; Van Oyen, H.; Vanhauwaert, E.; De Backer, G.; De Henauw, S.; Huybrechts, I. Dietary sources of energy and macronutrient intakes among Flemish preschoolers. Arch. Public Health 2011, 69, 5. [CrossRef]

38. European Food Information Council. Food-based dietary guidelines in Europe. Available online: http: //www.eufic.org/en/healthy-living/article/food-based-dietary-guidelines-in-europe (accessed on 16 March 2018).

39. Nutrition Information Centre, Belgium. De Actieve Voedingsdriehoek Voor Kleuters. Available online: http://www.123aantafel.be/03/03btabel2.html (accessed on 28 February 2018).

40. Cole, T.J.; Lobstein, T. Extended international (IOTF) body mass index cut-offs for thinness, overweight and obesity. Pediatr. Obes. 2012, 7, 284-294. [CrossRef]

41. Rodriguez, G.; Moreno, L.A.; Sarria, A.; Fleta, J.; Bueno, M. Resting energy expenditure in children and adolescents: Agreement between calorimetry and prediction equations. Clin. Nutr. 2002, 21, 255-260. [CrossRef]

42. Pinheiro, J.; Bates, D.; DebRoy, S.; Sarkar, D.; Team, R.C. Nlme: Linear and nonlinear mixed effects models. Available online: https://CRAN.R-project.org/package=nlme (accessed on 17 July 2018).

43. R Development Core Team. R: A language and environment for statistical computing; R Foundation for Statistical Computing: Vienna, Austria, 2015; Available online: http://www.R-project.org (accessed on 2 April 2018).

44. Baayen, R.H.; Davidson, D.J.; Bates, D.M. Mixed-effects modeling with crossed random effects for subjects and items. J. Memory Lang. 2008, 59, 390-412. [CrossRef]

45. Field, A.P.; Miles, J.; Field, Z. Discovering Statistics Using R.; SAGE Publications Ltd.: London, UK, 2012; p. 992.

46. Brown, R.; Ogden, J. Children's eating attitudes and behaviour: A study of the modelling and control theories of parental influence. Health Educ. Res. 2004, 19, 261-271. [CrossRef]

47. Dickens, E.; Ogden, J. The role of parental control and modelling in predicting a child's diet and relationship with food after they leave home a prospective study. Appetite 2014, 76, 23-29. [CrossRef]

48. Cooke, L.J.; Wardle, J.; Gibson, E.L.; Sapochnik, M.; Sheiham, A.; Lawson, M. Demographic, familial and trait predictors of fruit and vegetable consumption by pre-school children. Public Health Nutr. 2004, 7, 295-302. [CrossRef]

49. Draxten, M.; Fulkerson, J.A.; Friend, S.; Flattum, C.F.; Schow, R. Parental role modeling of fruits and vegetables at meals and snacks is associated with children's adequate consumption. Appetite 2014, 78, 1-7. [CrossRef] [PubMed]

50. Kristiansen, A.L.; Bjelland, M.; Himberg-Sundet, A.; Lien, N.; Andersen, L.F. Associations between sociocultural home environmental factors and vegetable consumption among Norwegian 3-5-year olds: BRA-study. Appetite 2017, 117, 310-320. [CrossRef]

51. Russell, C.G.; Haszard, J.J.; Taylor, R.W.; Heath, A.-L.M.; Taylor, B.; Campbell, K.J. Parental feeding practices associated with children's eating and weight: What are parents of toddlers and preschool children doing? Appetite 2018, 128, 120-128. [CrossRef] [PubMed]

52. Beets, M.W.; Tilley, F.; Kyryliuk, R.; Weaver, R.G.; Moore, J.B.; Turner-McGrievy, G. Children select unhealthy choices when given a choice among snack offerings. J. Acad. Nutr. Diet. 2014, 114, 1440-1446. [CrossRef] [PubMed]

53. Johnson, L.; van Jaarsveld, C.H.; Wardle, J. Individual and family environment correlates differ for consumption of core and non-core foods in children. Br. J. Nutr. 2011, 105, 950-959. [CrossRef]

54. Fisher, J.O.; Wright, G.; Herman, A.N.; Malhotra, K.; Serrano, E.L.; Foster, G.D.; Whitaker, R.C. Snacks are not food. Low-income, urban mothers' perceptions of feeding snacks to their preschool-aged children. Appetite 2015, 84, 61-67. [CrossRef]

55. Miguel-Berges, M.L.; Zachari, K.; Santaliestra-Pasias, A.M.; Mouratidou, T.; Androutsos, O.; Iotova, V.; Galcheva, S.; De Craemer, M.; Cardon, G.; Koletzko, B.; et al. Clustering of energy balance-related behaviours and parental education in European preschool children: The ToyBox study. Br. J. Nutr. 2017, 118, 1089-1096. [CrossRef]

56. Cardon, G.; De Bourdeaudhuij, I.; Iotova, V.; Latomme, J.; Socha, P.; Koletzko, B.; Moreno, L.; Manios, Y.; Androutsos, O.; De Craemer, M.; et al. Health related behaviours in normal weight and overweight preschoolers of a large pan-European sample: The ToyBox-Study. PLoS ONE 2016, 11, e0150580. [CrossRef] 
57. Whitaker, R.C.; Pepe, M.S.; Wright, J.A.; Seidel, K.D.; Dietz, W.H. Early adiposity rebound and the risk of adult obesity. Pediatrics 1998, 101, e5. [CrossRef]

58. Hill, C.; Llewellyn, C.H.; Saxton, J.; Webber, L.; Semmler, C.; Carnell, S.; van Jaarsveld, C.H.M.; Boniface, D.; Wardle, J. Adiposity and 'eating in the absence of hunger' in children. Int. J. Obes. 2008, 32, 1499-1505. [CrossRef]

59. Carnell, S.; Benson, L.; Gibson, E.L.; Mais, L.A.; Warkentin, S. Caloric compensation in preschool children: Relationships with body mass and differences by food category. Appetite 2017, 116, 82-89. [CrossRef] [PubMed]

60. Birch, L.L.; Fisher, J.O.; Davison, K.K. Learning to overeat: Maternal use of restrictive feeding practices promotes girls' eating in the absence of hunger. Am. J. Clin. Nutr. 2003, 78, 215-220. [CrossRef] [PubMed]

61. Manios, Y.; Androutsos, O.; Katsarou, C.; Vampouli, E.A.; Kulaga, Z.; Gurzkowska, B.; Iotova, V.; Usheva, N.; Cardon, G.; Koletzko, B.; et al. Prevalence and sociodemographic correlates of overweight and obesity in a large Pan-European cohort of preschool children and their families: The ToyBox study. Nutrition 2018, 55, 192-198. [CrossRef] [PubMed]

62. Llewellyn, C.; Wardle, J. Behavioral susceptibility to obesity: Gene-environment interplay in the development of weight. Physiol. Behav. 2015, 152, 494-501. [CrossRef] [PubMed]

63. Carnell, S.; Wardle, J. Appetite and adiposity in children: Evidence for a behavioral susceptibility theory of obesity. Am. J. Clin. Nutr. 2008, 88, 22-29. [CrossRef]

64. Dubois, L.; Farmer, A.P.; Girard, M.; Peterson, K. Preschool children's eating behaviours are related to dietary adequacy and body weight. Eur. J. Clin. Nutr. 2007, 61, 846-855. [CrossRef]

65. Gibson, E.L.; Cooke, L. Understanding food fussiness and its implications for food choice, health, weight and interventions in young children: The impact of Professor Jane Wardle. Curr. Obes. Rep. 2017, 6, 46-56. [CrossRef]

66. Russell, C.G.; Worsley, A.; Campbell, K.J. Strategies used by parents to influence their children's food preferences. Appetite 2015, 90, 123-130. [CrossRef]

(C) 2020 by the authors. Licensee MDPI, Basel, Switzerland. This article is an open access article distributed under the terms and conditions of the Creative Commons Attribution (CC BY) license (http://creativecommons.org/licenses/by/4.0/). 